\title{
RADIATION DOSIMETRY OF THE PRESSURE VESSEL INTERNALS OF THE HIGH FLUX BEAM REACTOR
}

\author{
Norman E. Holden, Richard N. Reciniello, Jih-Perng Hu, David C. Rorer \\ Brookhaven National Laboratory \\ Upton, New York 11973-5000, USA \\ E-mail: holden@bnl.gov
}

\begin{abstract}
In preparation for the eventual decommissioning of the High Flux Beam Reactor after the permanent removal of its fuel elements from the Brookhaven National Laboratory, both measurements and calculations of the decay gamma-ray dose rate have been performed for the reactor pressure vessel and vessel internal structures which included the upper and lower thermal shields, the transition plate, and the control rod blades. The measurements were made using Red Perspex ${ }^{\mathrm{TM}}$ polymethyl methacrylate high-level film dosimeters, a Radcal "peanut" ion chamber, and Eberline's high-range ion chamber. To compare with measured gamma-ray dose rate, the Monte Carlo MCNP code and geometric progressive MicroShield code were used to model the gamma transport and dose buildup.
\end{abstract}

\section{Introduction}

During its operational lifetime (1965-1996), the Brookhaven's High Flux Beam Reactor (HFBR) was a heavy water $\left(\mathrm{D}_{2} \mathrm{O}\right)$ cooled and moderated reactor. There were 28 highly enriched uranium fuel elements ( $93 \%$ of ${ }^{235} \mathrm{U}$-enrichment). The height of the pressure vessel enclosing the core is $2823 / 4^{3}$ from the bottom of the spherical section holding the core to the top of the cylindrical section's cover plate (255" to the top of the vessel), as shown in Figure 1. At the height at which the spherical section is joined to the cylindrical section is a gridded steel disk, the Transition Plate. It is type-304 stainless steel, $1 / 2$ " thick. Control rod drives run through the grid apertures and the top of the fuel element assemblies were at the bottom of the Transition Plate. After the final shutdown on December 21, 1996, all of the fuel was removed. The Control Rod Drive blades that were made of Europium-Dysprosium oxides $\left(\mathrm{Eu}_{2} \mathrm{O}_{3}\right.$ and $\left.\mathrm{Dy}_{2} \mathrm{O}_{3}\right)$ are located in a region 4 " from the bottom of the vertical irradiation tubes (V-13 and V-14). At the time of the measurements ( 40 months after the final shutdown), the only radioactive nuclides still remaining in the control rod blades were ${ }^{152} \mathrm{Eu},{ }^{154} \mathrm{Eu}$, and ${ }^{155} \mathrm{Eu}$.

The HFBR has 9 horizontal beam tube penetrations (H-1 to H-9) for neutron scattering to take advantage of the thermal neutron flux peaking in the reflector region outside the core, as depicted in Figure 2. There were also 7 vertical tubes (V-10 to V-16) for introducing samples in the reactor to be irradiated. Three (V-10, V-11, V-12) were in the core reflector, two (V-13, V-14) were in the core edge and two (V-15, V-16) were in-core. One (V-13) was a vertical fixed port that had items placed in it from the HFBR's inception for material surveillance, but was replaced in the 1990's by a mirror of V-14.

After final HFBR shutdown, there was a period of nearly 3 years during which HFBR staff performed work on the supporting systems, for environmental compliance reasons. In November 
1999, however, the Department of Energy (USDOE) decided that the HFBR would remain permanently shutdown. Accordingly, plans were then made for eventual decommissioning. In preparation for removal of internal vessel components, initial Monte Carlo (MCNP [1]) calculations were performed. Also, data from a consulting firm, initially calculated for a possible replacement of the pressure vessel, was reviewed [2]. Earlier, preliminary measurements (AugustSeptember 1999) with a lowered water column, suggested that these values might be high. Accordingly, MicroShield [3] was used to estimate dose from the Transition Plate, using the dose rate measurement with a lowered water column as a basis. Initial measurements were made to estimate the dose rate from vessel internal components. These initial measurements, involving the Transition Plate (using the RO-7 ion chamber), were made in March 2000, followed in April by the measurement of dose using high range film inserted into irradiation tubes V-13, V-14 (on either side of the core) and V-10 at several depths in the pressure vessel. MCNP-4B2 calculations of activity for vessel components were made at this time, using activation data from the HFBR operational log. The "peanut" ion chamber measurements were taken in December 2000. This involved dose rates at various depths in irradiation tube $\mathrm{V}-10$. Various subsequent confirmatory measurements were taken in 2001.

At the time of these measurements, all items other that the transition Plate and the Control Rod Drive blades had been removed from the pressure vessel. The vessel was filled with $\mathrm{D}_{2} \mathrm{O}$ heavy water during all of these measurements, so there were no density differences that had to be taken into account. As stated above, all fuel elements had been removed prior to these measurements. The dose measure, therefore, would be solely due to gamma rays emitted from internal vessel components that had been activated during the $30^{+}$-years of operation of the HFBR.

\section{Transition Plate RO-7 Measurement and MCNP Comparison}

Actual measurements of the gamma ray dose rate from the Transition Plate were made using an RO-7 dose rate meter. The RO-7 is an ion chamber manufactured by Eberline, Inc. designed for underwater high gamma-ray dose rate measurements. The upper bound is $20,000 \mathrm{R} / \mathrm{h}$. The listed (Thermo-Eberline instrument specifications) measurement uncertainty in the energy range from 33 $\mathrm{KeV}$ to $6 \mathrm{MeV}$ is $\pm 15 \%$.

Activity calculations were performed (April, 2000) using MCNP. code to estimate the activation product activity of the Transition Plate. The specific code used was Monte Carlo based MCNP-4B2. ENDF/B-VI continuous neutron cross-section data were used with a thermal power estimate (in MWh) from HFBR operation logs (employing the $\mathrm{D}_{2} \mathrm{O}$, thermal neutron scattering function). Calculated flux at the Transition Plate averaged $6.0 \times 10^{13}: \mathrm{n} / \mathrm{cm} 2 / \mathrm{s}$ at $60 \mathrm{MW}$ and was normalized for operation at $40 \mathrm{MW}$ (1960's and 1970's) and $30 \mathrm{MW}(1990$ 's) [4,5]. Cobalt content was $1,414 \mathrm{ppm}$ [5] for type-304 stainless steel(NUREG/CR 3474). Using these figures, a 12,410 Ci Transition Plate Co-60 activity was calculated as of 3/1/00. This was less than the activity projected by consultants hired to estimate activity (and dose rate) from vessel components in the eventuality of a vessel replacement.

In August 1999, prior to draining the reactor vessel, the water level in the vessel was dropped 12 " so that the reactor operations group could perform certain measurements. Dose rate measurements were taken at the top of the vessel. With the water level reduced from full (nominally 120") to $108^{\prime \prime}$, a dose rate increase was expected. The magnitude of the increase, to $180 \mathrm{mR} / \mathrm{h}$ (from 1-2 $\mathrm{mR} / \mathrm{h}$ at 120 "), was less than what would have been expected had the Transition Plate activity been at the level predicted by the consulting firm (with an estimated contact dose rate of $>10^{5} \mathrm{R} / \mathrm{h}$ ). MicroShield code was employed using the measured $180-\mathrm{mR} / \mathrm{h}$ dose rate to estimate the Transition Plate activity at $2,550 \mathrm{Ci}$. Since the HFBR had, at this time, been shutdown for over $3 \frac{1}{2}$ years, all activity was assumed to be Co-60. Using this estimated activity, the dose rate at contact with the center of the plate was calculated to be $17,200 \mathrm{R} / \mathrm{h}$.

On March 29, 2000, an RO-7 was used to measure the activity at or near contact with the 
Transition Plate. The vessel level had been brought back to 120 " $\left(\mathrm{D}_{2} \mathrm{O}\right)$. The measurements were taken laterally, moving slowly from the edge of the Transition Plate to its center. The detector is recessed 3" inside the housing. At the edge, a dose rate of $12,000 \mathrm{R} / \mathrm{h}$ and a dose rate of 16,000 $\mathrm{R} / \mathrm{h}$ were measured at contact ( 3 " detector distance) with the center. This agreed within $\pm 7 \%$ of the estimate using MicroShield code, thus validating the Co-60 activity estimate of $2,550 \mathrm{Ci}$.

\section{High Dose Film Measurement}

The high dose film used was "Red Perspex". This is a polymethyl methacrylate film, manufactured by Port Plastics, Sunnyvale, California. These were given to the Brookhaven National Laboratory (BNL) and later measured by the staff in dosimetry section at the Stanford Linear Accelerator (SLAC) [6]. The dose-rate range for the film was from 0.1 million rads, integrated dose, to 5 million rads, integrated dose. The film was read on a Macbeth Quantalog Optical Densitometer, with a 1\% resolution error (GretagMacbeth specifications).

The films were received from SLAC. During April-May, 2000 the films were placed into vertical tubes at different depths for exposure. The films were returned to SLAC for dose determination after exposure. The dose data was then transmitted to BNL. The tubes employed were the core edge V-13 and V-14, and V-10 in the reflector. V-13 and V-14 were on opposite sides of the core at azimuthal angles $139^{\circ}$ and $319^{\circ}$, respectively. Tube V-10 was at an azimuthal angle of $46^{\circ}$ and is 28 inches lateral to the core center. For reference, the neutron flux, measured in tube V-14 in 1996 was $(1.06 \pm 0.08) \times 10^{15} \mathrm{n} / \mathrm{cm} 2 / \mathrm{s}$, and in $\mathrm{V}-10,(1.59 \pm 0.10) \times 10^{14}$ [7]. These were employed due to proximity to the Control Rod Drive blades and to the Transition Plate [8]. The irradiation times were varied such that total dose to the films were between 100,000 rads and 750,000 rads. The following Table 1 shows the dose rate at each of the irradiation tube depths, and the nearness to vessel internal components.

Table 1: Red Perspex high range dose rates in HFBR vertical irradiation tubes

\begin{tabular}{|c|c|l|c|}
\hline $\begin{array}{c}\text { Vertical } \\
\text { Tube }\end{array}$ & $\begin{array}{c}\text { Height above Tube } \\
\text { Bottom (inches) }\end{array}$ & Vessel Internal Components in Area & $\begin{array}{c}\text { Gamma Dose Rate } \\
(\mathrm{R} / \mathrm{h})\end{array}$ \\
\hline V-13 & 4 & Level with Control Rod Blades & 2,825 \\
\hline V-14 & 4 & Level with Control Rod Blades & 10,160 \\
\hline V-13 & 33 & Level with lateral edge of TR Plate & 5,925 \\
\hline V-14 & 33 & Level with lateral edge of TR Plate & 11,480 \\
\hline V-13 & 36 & $3^{\text {" above edge of TR Plate }}$ & 8,800 \\
\hline V-10 & 7 & & 1,630 \\
\hline
\end{tabular}

\section{4. "PEANUT" Ion Chamber Dose Rate Measurement}

The unit inserted into vertical irradiation tube V-10 to measure gamma dose rate at various depths in the tube was the Radcal Model 9015 ion chamber. This is a $0.6-\mathrm{cm}^{3}$ ion chamber, with a maximum dose rate of $8,000 \mathrm{R} / \mathrm{min}$. ( 0.48 million $\mathrm{R} / \mathrm{h})$. The accuracy of the reading is listed (Radcal instrument specifications) as $\pm 4 \%$. As noted above, $V-10$ is in the core reflector, with an azimuthal angle at $46^{\circ}$. In the depths at which the first several measurements were taken, the distance to the core is between 34.4 inches and 40.8 inches. For comparison, the high dose rate film was exposed at a depth of 15 feet and 8 inches ( 7 inches above the bottom) at a distance from the core center of 29.9 inches.

The measurements were taken in December 2000 [9]. As with the other vessel measurements, the vessel was filled with Heavy water $\left(D_{2} O\right)$. The tube has a nominal depth of $16 \frac{1 / 2}{2}$ feet. Insertion distance was limited to $14 \frac{1}{2}$ feet due to increased resistance from the plastic anticontamination 
sleeve placed around the ion chamber. Dose rate measurements were taken at $1 / 2$ feet intervals to the top of the tube.

The dose rate at the maximum insertion depth of $141 / 2$ feet is $1,620 \mathrm{R} / \mathrm{h}$. This is both above and lateral to the plane of the Control Rod Blades. Table 2 lists the value at various depths in V-10.

Table 2. Ion chamber dose rates in vertical tube V-10

\begin{tabular}{|c|c|l|}
\hline Depth in V-10 & Gamma-Ray Dose Rate $(\mathrm{R} / \mathrm{h})$ & Distance to Internal Components*, etc. \\
\hline $14.5 \mathrm{ft}$. & 1,620 & Approximately 1 ft. above Red Perspex \\
\hline $14.0 \mathrm{ft}$. & 2,282 & Below Approximate Plane of TR Plate \\
\hline $13.5 \mathrm{ft}$. & 2,166 & Above Approximate Plane of TR Plate \\
\hline $13.0 \mathrm{ft}$. & 1,912 & \\
\hline $12.5 \mathrm{ft}$. & 1,007 & \\
\hline $12.0 \mathrm{ft}$. & 151 & \\
\hline $11.5 \mathrm{ft}$. & 78 & \\
\hline $11.0 \mathrm{ft}$. & 31 & \\
\hline $10.5 \mathrm{ft}$. & 8.6 & \\
\hline $10.0 \mathrm{ft}$. & 2.8 & \\
\hline $9.5 \mathrm{ft}$. & 2.9 & \\
\hline $9.0 \mathrm{ft}$. & 1.9 & \\
\hline $8.5 \mathrm{ft}$. & 2.2 & \\
\hline $8.0 \mathrm{ft}$. & 1.7 & \\
\hline $7.5 \mathrm{ft}$. & 1.7 & \\
\hline $7.0 \mathrm{ft}$. & 0.9 & \\
\hline $6.5 \mathrm{ft}$. & 0.4 & \\
\hline
\end{tabular}

(* The distance measurements in Table 2 are from the top of the irradiation tube and denote the depth (from the top) at which the gamma-ray dose rate was measured.)

Above 6 feet (from the top of the irradiation tube) the dose rate is 0 as measured with the "peanut" ion chamber. This is at the depth whence the tube emerges from the outer edge of the reactor shield. Note that, from a depth of 10-6.5 feet, the dose rate decreases only gradually, as the tube is inside the shield and the measurements are distanced from the activity sources. Note also the transition range from 12.5-10.5 feet where the dose rate drops sharply from $1,000 \mathrm{R} / \mathrm{h}$ to $<10$ $\mathrm{R} / \mathrm{h}$. The bottom of $\mathrm{V}-10$ is 2 feet below the 14.5 feet measurement.

\section{Discussion and Comparison of Results}

As has been noted, dose rate in the reactor vessel is due to gamma rays from activated metal components inside the vessel. The components at the time of the measurements are the Transition Plate and the Control Rod Drive blades. The former is located at the "neck" whence the rounded vessel segment that had contained the core is joined to the tubular structure sitting atop. The latter are located in the bottom section of the rounded vessel segment, in a plane about 4 inches above the bottom of tubes V-13 and V-14.

Both a Red Perspex high-range film measurement and a "peanut" ion chamber measurement were taken in tube V-10. At an azimuthal angle of $46^{\circ}$, the slope of rise of the tube is much less acute than for V-13 and V-14. The distance to the core at the depth of the "peanut" ion chamber measurement is 34 inches. The bottom of the tube is 7 inches above the core mid-plane, and the "peanut" ion chamber was positioned at 14.5 feet into the tube. The distance to the core from the Red Perspex measurement (also in V-10) was 29.9 inches. Each of the measurements was, therefore, taken at a similar distance from the Control Rod Drive blades. This is borne out by the 
dose rate similarity; $1,620 \mathrm{R} / \mathrm{h}$ using the "peanut" ion chamber, and 1,630 R/h using Red Perspex. This indicates that the difference in distance from the "peanut" ion chamber measurement to the point of the Red Perspex measurement is lateral, with the distances from the activity source (Control Rod Drive blades) to the point of each measurement virtually the same.

The RO-7 ion chamber measured the dose rate laterally from the above the inner edge of the Transition Plate to the middle of the plate. The dose rate measured by the RO-7 at 3 inches above the edge of the Transition Plate is $\sim 12,000 \mathrm{R} / \mathrm{h}$. One of the high range Red Perspex films was placed in tube V-13, at an approximate distance 3 inches above the plane of the Transition Plate. The Transition Plate has a nominal radius of approximately 12 inches and is only 0.5 inches thick. Since V-13 is in the core edge, it is slightly greater than 2 inches lateral to the Plate and 11.3 inches from the core (at the point of this measurement). A drop in dose rate $(12,000 \mathrm{R} / \mathrm{h}$ to 8,800 $\mathrm{R} / \mathrm{h}$ ) would, therefore be expected as one goes outward from the center of the planar Transition Plate activity source.

It is interesting to note that the Red Perspex films inserted at an equal distance into V-13 and V-14 were not measured with the same dose. Each of the films was inserted at the plane of the Transition Plate. The V-13 and V-14 tubes are equi-distant from the reactor core (V-13 at $139^{\circ}$ and V-14 at $319^{\circ}$ azimuthally). That the dose rate is lower than that measured with the RO-7 may be explained by the increased lateral distance from the center of the planar Transition Plate activity source. The dose rate in the V-13 tube is $5,930 \mathrm{R} / \mathrm{h}$ and that in V-14 (same plane, opposite side of the core) is $11,374 \mathrm{R} / \mathrm{h}$. There are several possible explanations. One is that the lower activity control rod blades had been replaced at a later date than those on the opposite side. They would, therefore, have less time in-core to be activated. Neutron flux, and fast flux to thermal flux ratios also might be different, depending upon the age of the fuel in the rods adjacent to the points at which the measurements were taken.

The dose rate at the plane of the Control Rod Drive blades also exhibits this phenomenon. The dose rate in V-13 at the plane of the Control Rod Drive blades is $2,850 \mathrm{R} / \mathrm{h}$, and the dose rate measured in V-14 is 4 times higher, or 11,374 rem.

The above data also provides a clue to the difference between the activity of the Transition Plate calculated from the RO-7 measurement and the activity predicted by MCNP calculation. The dose rate differences indicate local flux differential. The reactor power, nominally $40 \mathrm{MW}, 60$ $\mathrm{MW}$ or $30 \mathrm{MW}$ varied about this nominal value during the period of reactor operations. Fuel rods were rotated during every reactor outage. This directly affected the local neutron flux, as well as the fast to thermal neutron flux ratio. These factors tend to normalize theoretical calculations to fit actual data. The factor of 4.9 difference between activity predicted by calculation and that calculated from actual measurement is, therefore, fairly good agreement.

\section{Conclusions}

Several conclusions can be drawn from the data presented above. The most obvious conclusion is that the shield around the HFBR Reactor Vessel is adequate to keep dose outside the shield as low as reasonably achievable (ALARA).

A second conclusion is that data collected by various methods and instruments can closely agree and point to the same conclusions. It must be stressed, however, that this is only true if the parameters are well defined and understood by all experimental personnel. The high range film dose data, the "peanut" ion chamber dose rate data and the RO-7 dose rate measurements all were in good agreement. This was possible because the parameters were well defined. The distances from the core, and from the activity source to the dose measurement points were calculated for each of the dose measurement methods. The exposure times for the Red Perspex film was optimized to the mid point of the linear response range. The configuration of internal vessel components was known. A comparison of the dose rate measurement methods was, therefore, 
possible, due to normalization by defining the parameters at which the dose rates were measured.

These data measurements point out that, given such defined parameters, different instruments and methods may be used for radiological measurements in a reactor vessel [10]. This could prove important given local constraints such as size, dose intensity, or the medium of the measurement (i.e. water). The defined parameters normalize the results obtained from different methods and instrument measurements such that the appropriate comparisons may be made.

\section{Acknowledgement and Disclaimer}

This research was supported in part by the US Department of Energy under the contract DEAC02-98CH10886.

Please note that the above dimensions and measurement data are in English units. The manuals describing the High Flux Beam Reactor, and the dimensions and measurements contained therein, being first printed in the 1960's, are given in English units. For the sake of consistency, we have continued with these.

\section{References}

[1] US-DOE/Los Alamos National Laboratory, MCNP4B2-Monte Carlo N-Particle Transport Code System, distributed by the RSICC of the Oak Ridge National Laboratory (1997).

[2] WMG Presentation, Disposition Alternatives (for the) HFBR Vessel and Internals (2000).

[3] C. A. Negin and G. Worku, MicroShield (ver.4), Grove Engineering, Inc. (1992).

[4] L. Chang, "Dose Estimates for the HFBR Control Assemblies and Transition Plate", $B N L$ Memorandum (2000).

[5] N. E. Holden, et al., Updated Flux Information for Neutron Scattering \& Irradiation Facilities at the BNL HFBR, Int. Conf. on Nucl. Data for Sci. \& Tech., p.246 (1997).

[6] N. E. Ipe and J. C. Liu, High Level Dosimetry at the Stanford Linear Accelerator, SLAC Publication, 5686 (1991).

[7] N. E. Holden, et al., BNL High Flux Beam Reactor Pressure Vessel Measurements, $B N L$ Internal Report (2000).

[8] N. E. Holden; Use of Polymethyl Methacrylate Dosimeters to Estimate HFBR Dose Rates, $B N L$ Memorandum (2000).

[9] N. E. Holden, private communication (2002).

[10] N.E. Holden, et al., Radiation Dosimetry at the BNL High Flux Beam Reactor and the Medical Research Reactor, ASTM-STP-1398, p.223 (1998). 


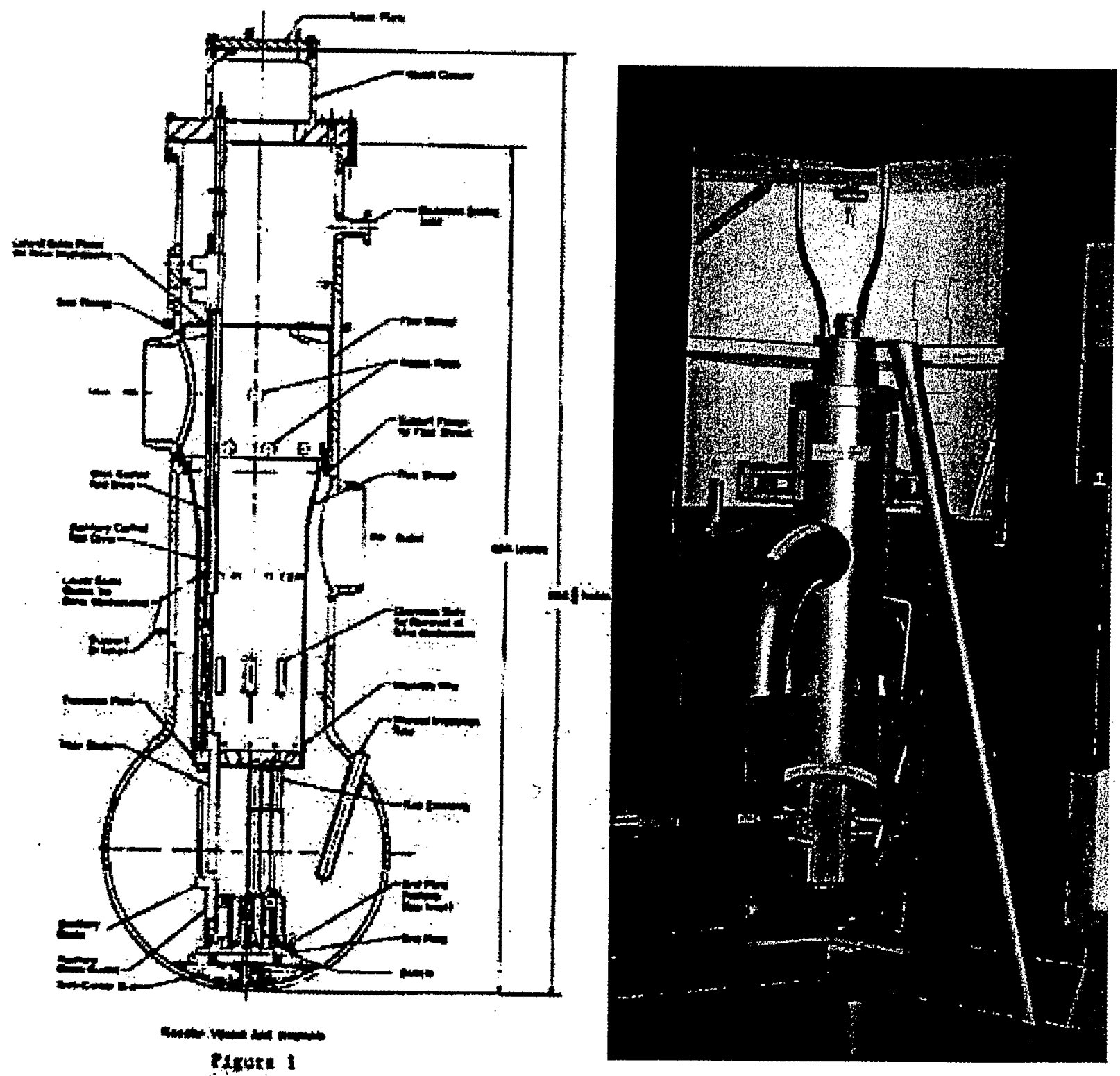

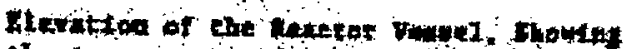

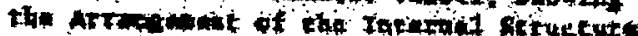

Figure 2. Reactor Model Photograph 